\title{
Pelayanan Informasi Obat Pada Kader Puskesmas dan Sosialisasi Bahaya Narkoba Pada Anak Sekolah di Kota Kendari
}

\author{
Sunandar Ihsan ${ }^{1 *}$, Sabarudin ${ }^{1}$, La Ode Muhammad Fitrawan ${ }^{1}$, Nuralifah $^{1}$, Muhammad Arba $^{1}$, Wa \\ Ode Sitti Nurrokhmadhani ${ }^{2}$
}

${ }^{1}$ Fakultas Farmasi Universitas Halu Oleo, Kampus Hijau Bumi Tridharma Anduonohu Jl. H. E. A. Mokodompit Kendari 93232

${ }^{2}$ Puskesmas Mokoau, Kompleks BTN Kendari Permai, Kelurahan Padaleu, Kecamatan Kambu, Kota Kendari 93231

E-mail: sunandarihsan@uho.ac.id

\begin{abstract}
Abstrak
Kegiatan sosialisasi DAGUSIBU (Dapatkan Gunakan Simpan Buang) metode Cara Belajar Insan Aktif/CBIA pada kader Puskesmas Mokoau dan sosialisasi bahaya Narkoba pada siswa sekolah menengah atas di Kota Kendari telah dilaksanakan oleh tim Pengabdian Kepada Masyarakat Fakultas Farmasi UHO. Tujuan dari kegiatan sosialisasi DAGUSIBU metode CBIA adalah untuk meningkatkan pengetahuan masyarakat terkait cara penggunaan obat yang baik dan benar melalui komunitas tertentu di masyarakat, dan sosialisasi Narkoba bertujuan untuk memberi pengetahuan mengenai modus-modus penyebaran Narkoba serta bahaya dan bentuk-bentuk penyalahgunaan obat termasuk Narkoba jenis baru. Kegiatan sosialisasi DAGUSIBU metode CBIA dilakukan pada Kader Puskesmas Mokoau berjumlah 22 orang dibagi dalam 4 kelompok dipandu oleh Master AoC Gema Cermat Kemenkes RI utusan Kota Kendari. Tahap, pertama pemberian penjelasan umum tentang Gerakan Masyarakat Cerdas Menggunakan Obat/GEMA CERMAT dan DAGUSBU, kedua tiap peserta diberikan kuisioner pretest untuk mengetahui tingkat pengetahuan peserta sebelum sosialisasi. Kegiatan inti adalah peserta mengelompokkan obat-obat yang diberikan dalam formulir yang telah dibagikan berdasarkan kandungan zat aktif untuk di identifikasi nama dagang, indikasi, efek samping dan kontraindikasi yang ada pada kemasan obat dengan di fasilitasi oleh seorang Apoteker. Kegiatan akhir adalah peserta mempresentasikan hasil diskusi salah satunya tentang tidak ada perbedaan antara obat generik dan bermerek pada kualitas dan efektivitasnya untuk indikasi penyakit yang sama. Selain itu pada cara penyimpanan harus sesuai bentuk sediaan obat dan pemusnahan obat yang di pisahkan dari kemasan primernya dengan cara ditanam dalam tanah. Posttest dilakukan untuk menilai tingkat pengetahuan setelah kegiatan. Sosialisasi Narkoba dilakukan di dilakukan di SMA 1 Kendari oleh 3 orang peserta 207 orang, SMA 4 Kendari oleh 4 orang apoteker dengan jumlah peserta 1669 orang, SMA 9 Kendari oleh 3 orang apoteker dengan jumlah peserta 916 orang, SMK 2 Kendari oleh 3 orang apoteker dengan jumlah peserta 324 orang dan SMK 4 Kendari oleh 3 Apoteker dengan jumlah peserta 579 orang. Kegiatan tersebut bekerjasama dengan Pengurus Daerah Ikatan Apoteker Indonesia Sulawesi Tenggara dan Badan Narkotika Nasional Provinsi Sulawesi Tenggara.
\end{abstract}

Kata kunci: Dagusibu, CBIA, Narkoba, Gema Cermat, Farmasi, Halu Oleo

\section{Pendahuluan}

Obat memainkan peran yang sangat penting dalam pelayanan kesehatan demi tercapainya kesehatan pasien, namun penggunaan obat yang rasional masih menjadi masalah terbesar dalam tercapainya terapi yang efektif dan efisien. Penggunaan obat yang rasional meliputi tepat dalam hal indikasi, tepat pasien, tepat dosis, tepat obat dan tepat cara dan lama penggunaan. Akan tetapi dalam laporan yang diterima oleh World Helath Organization (WHO) masih terdapat penggunaan obat yang tidak rasional dimana terdapat lebih dari $50 \%$ dari seluruh penggunaan obatobatan tidak tepat dalam peresepan, penyiapan, ataupun penjualannya, sedangkan $50 \%$ lainnya tidak digunakan secara tepat oleh pasien. Oleh karenanya keamanan pasien merupakan tujuan utama pelayanan kefarmasian.
Ketidakrasionalan penggunaan obat juga berakibat pada pemborosan biaya terutama resistensi antibiotik akibat penggunaan obat yang tidak rasional. Kerugian yang dilaporkan menghabiskan biaya US \$4-5 miliar pertahun di Amerika Serikat dan €9 miliar di Eropa), akibat terjadinya reaksi obat yang merugikan dan kesalahan pengobatan [1]. Maraknya penyalahgunaan obat dan penggunaan obat yang salah dapat disebabkan oleh ketidaktahuan masyarakat pengguna terkait bahaya dari obat yang tidak rasional yang berdampak pada kerugian ekonomi. Oleh karena itu salah satu cara mengedukasi masyarakat adalah dengan sosialisasi DAGUSIBU tentang penggunaan obat yang baik dan benar agar masyarakat cerdas dalam menggunakan obat. Sosialisasi DAGUSIBU dapat dilakukan dengan metode Cara Belajar Insan Aktif atau CBIA. Metode CBIA 
pertama kali diinisiasi oleh Fakultas Farmasi Universitas Gadjah Mada bagian Farmakologi Klinik tahun 1993 dan kemudian diadaptasi oleh Departemen Kesehatan tahun 2008 [2]. Oleh Ikatan Apoteker Indonesia DAGUSIBU metode CBIA dijadikan sebagai model pemberian informasi obat pada masyarakat untuk mendukung program pemerintah Kementrian Kesehatan yaitu Gerakan Cerdas Menggunakan Obat atau Gema Cermat.

Metode CBIA efektif dalam meningkatkan pengetahuan peserta yaitu ibu-ibu tentang penggunaan obat yang baik dan benar dalam pengobatan sendiri atau swamedikasi [2]. Dibanding dengan metode snowball throwing, metode CBIA memiliki efektivitas yang sama dalam meningkatkan pengetahuan ibu tentang penggunaan obat dalam swamedikasi [3]. Oleh karena itu pemilihan sosialisasi Dagusibu metode CBIA diharapkan efektif dalam peningkatan pemahaman peserta tentang penggunaan obat yang baik dan benar.

Pada penyalahgunaan obat yang lain, narkoba masih menjadi masalah utama dimana pelaku penyalahgunaan narkoba di Sulawesi Tenggara tahun 2015 mencapai 26.357 orang sedangkan data dari BNN pada akhir tahun 2017, terdapat sebanyak 58.365 tersangka [4]. Sebanyak 66 persen atau 17.402 pengguna masih berstatus pelajar dan 34 persen atau 8.965 orang terdiri dari PNS, karyawan swasta dan aparat hukum [5]. Tingginya penyalahgunaan narkoba terutama di kalangan pelajar membutuhkan perhatian dan penanganan yang lebih komprehensif. Salah satu yang dapat dilakukan adalah dengan memberikan informasi dan pengetahuan sejak dini terutama tentang bahaya narkoba untuk memberikan kesadaran pada tingkat bawah sadar tentang bahaya penggunaan narkoba yang tidak tepat. Peran apoteker dalam sangat diperlukan karena apoteker adalah bukan saja sebagai penanggungjawab tentang informasi obat tetapi juga dalam hal distribusi obat. Peran ini dapat diwujudkan melalui organisasi Ikatan Apoteker Indonesia/IAI untuk bersama-sama bergerak dan berkomitmen mencegah dan memberantas peredaran gelap narkoba bukan semata-mata tugas Badan Pengawas dan Obat Makanan/BPOM atau Badan Narkotika Nasional/ BNN.

Tujuan kegiatan ini adalah untuk peningkatan pengetahuan masyarakat terhadap penggunanan obat yang baik dan benar serta pencegahan pada penyalahgunaan obat. Selain itu juga untuk membentuk Gerakan Kelompok Masyarakat Sadar Obat (GKSO) dalam pengobatan sendiri sebagai role model penggunaan obat yang baik dan benar bagi masyarakat sekitarnya yang mendukung program Kementrian Kesehatan Gerakan Masyarakat Cerdas Menggunakan Obat (Gema Cermat). Sasaran kegiatan adalah anak sekolah untuk sosialisasi Narkoba dan kader Puskesmas untuk dagusibu. Dengan kegiatan pengabdian pada masyarakat berupa pemberian informasi obat diharapkan masyarakat akan menggunaan obat dengan baik dan benar dan anak sekolah terhindar dari penyalahgunaan narkoba.

\section{Metode}

Sosialisasi Narkoba dilakukan dengan bekerjasama dengan Pengurus Daerah Ikatan Apoteker Indonesia
Sulawesi Tenggara (PD IAI) dan Badan Narkotika Nasional Provinsi (BNNP) melalui program kerja PD IAI Sultra pada pencanangan sosialisasi narkoba PD IAI dan BNNP.

Sosialisasi Dagusibu dilakukan di Puskesmas pada Kader Puskesmas sebagai wakil puskesmas di masyarakat. Sosialisasi Dagusibu menggunakan metode Cara Belajar Insan Aktif/CBIA bekerjasama dengan Apoteker sebagai Master AoC Gema Cermat Kementrian Kesehatan wakil Kota Kendari. Metode CBIA dilakukan dengan membagi peserta menjadi beberapa kelompok kecil dengan masingmasing 1 orang fasilitator apoteker tiap kelompok. Setiap peserta diberikan kuisioner pre dan posttest untuk menilai tingkat pengetahuan peserta mengenai penggunaan obat. Setiap kelompok diberi satu paket obat-obatan dan mengelompokan berdasarkan nama obat dan kandungan yang sama, indikasi, efek samping dan kontraindikasinya yang dipandu oleh Apoteker. Akhir kegiatan dilakukan diskusi antar peserta untuk mengkonfirmasi hasil yang didapat selama diskusi di kelompok masing-masing. Terakhir diberikan kuisioner posttest. Selain itu digunakan leaflet Dagusibu dan leaflet informasi Narkoba dari BNN.

\section{Hasil dan Pembahasan}

\subsection{Sosialisasi Narkoba}

Kegiatan sosialisasi Bahaya Narkoba ini dilakukan pada para pelajar di SMA 1, SMA 4, SMA 9, SMK 2, SMK 4 Kota Kendari yang dilaksanakan di Lapangan Upacara masing-masing sekolah pada hari Rabu, 25 Juli 2018 sampai Oktober 2018 pukul 07.00 WITA sampai 08.00 WITA. Kegiatan ini dilakukan pada pelajar untuk mengetahui dari bahaya penyalahgunaan dan modus penyebaran Narkoba serta konsekuensi hokum dari pemakai dan atau pengedar Narkoba serta solusi agar terhindar dari jerat Narkoba. Salah satu yang disampaikan dalam sosialisasi Narkoba adalah bentuk-bentuk penyalahgunaan Narkoba seperti terjadi dalam masyarakat saat ini seperti mengkonsumsi dengan dosis yang berlebihan, memperjualbelikan tanpa ijin serta melanggar aturan yang ditetapkan dalam UU No.35 Tahun 2009 tentang Narkoba. Selain itu juga disampaikan modus penyebaran narkoba melalui orang tak dikenal dibandara atau kiriman yang tak dikenal.

Kegiatan sosialisasi ini dilaksanakan pada pagi hari agar kegiatan tersebut berjalan dengan baik dan para pelajar dapat memahami materi yang akan diberikan. Kegiatan ini diikuti oleh seluruh pelajar SMA 1, SMA 4, SMA 9, SMK 2, SMK 4 Kota Kendari. Peserta yang mengikuti sosialisasi dari SMA 1 berjumlah 207 orang dengan 3 orang Apoteker, SMA 4 berjumlah 1.668 orang dengan 4 orang Apoteker, SMA 9 berjumlah 916 orang dengan 3 orang Apoteker, SMK 2 berjumlah 324 orang dengan 3 orang Apoteker, SMK 4 berjumlah 579 orang dengan 3 orang Apoteker, dengan total peserta adalah 3694 orang, dalam kegiatan ini Badan Narkotika Nasional Provinsi Sulawesi Tenggara dan Ikatan Apoteker Indonesia Provinsi Sulawesi Tenggara berperan sebagai pemateri. Setelah itu diberikan pesanpesan kepada pelajar mengenai bahaya Narkoba itu sendiri 

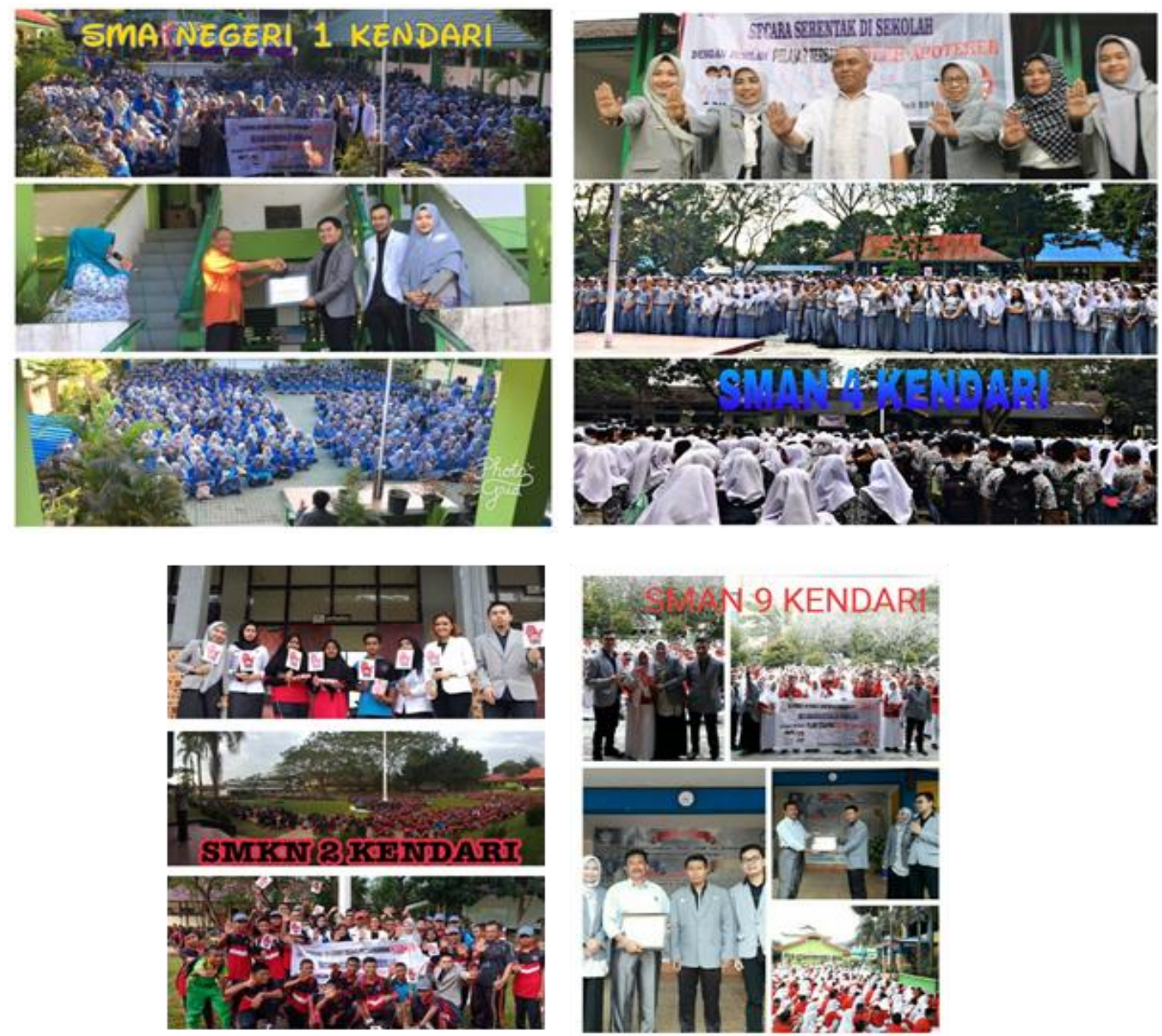

Gambar 1. Sosialisasi Narkoba di beberapa Sekolah Menengah Atas di Kota Kendari

yang dilanjutkan dengan pemberian cinderamata dan dilanjutkan dengan foto bersama.

Anak Sekolah sangat perlu untuk terus di ingatkan dan di edukasi tentang bahaya Narkoba terutama modus penyebaran dan bentuk penyalahgunaan zat adiktif yang semakin beragam. Jenis narkotika yang sering disalahgunakan pada pelaku hiburan malam yang diperiksa di RS Bhayangkara Kota Kendari adalah tetrahidrokanidol (ganja), amfetamin dan metamfetamin dengan rentang usia terbanyak pada 26-35 tahun [7]. Sosialisasi Narkoba pada anak sekolah sebaiknya diberikan dalam bentuk media visual berupa film pendek kreatif untuk memberi kesan mendalam. Selain itu sosialisasi narkoba dapat dilakukan melalui gerakan kampanye oleh anak sekolah itu sendiri agar mereka ikut terlibat dan menjadi bagian dari komunitas besar yang memiliki tujuan yang sama dengan seluruh masyarakat peduli Narkoba sehingga memunculkan sifat peduli.

Penggunaan alat bantu berupa leaflet dan media audio visual membantu dalam sosialisasi narkoba untuk menanamkan kesadaran pada peserta tingkat anak sekolah. Dalam pengabdian ini diproduksi sebuah film pendek yang disutradarai oleh Ahmad Nizar dari CV. Tenggara Production dengan judul 'Sesal' berdurasi 9 menit. Film pendek ini bercerita tentang seorang mahasiswa pecandu narkoba yang harus kehilangan ayahnya akibat kelelahan dalam mencari biaya untuk sang anak yang terlilit hutang SPP akibat dipakai untuk membeli narkoba.

\subsection{Pelayanan Informasi Obat di Puskesmas dengan Dagusibu Metode CBIA}

Pemberian informasi obat adalah bagian dari pelayanan kefarmasian di puskesmas yang bertujuan untuk menjamin patient safety. Dalam standard pelayanan kefarmasian di puskesmas, pelayanan informasi obat harus dilakukan oleh apoteker [6]. Dalam kegiatan pengabdian ini pemberian informasi obat dilakukan melalui Dagusibu metode CBIA dengan sebelumnya berkoordinasi dengan pihak Puskesmas Mokoau dan survei lapangan. Koordinasi dilakukan dengan Kepala Puskesmas Mokoau untuk mendapatkan perijinan dan sekaligus meninjau lokasi kegiatan dalam rangka persiapan pelaksanaan. Koordinasi dilakukan dengan tujuan agar kegiatan pengabdian mendapatkan izin dari Kepala Puskesmas Mokoau sehingga kegiatan dapat berjalan dengan lancar.

Dagusibu adalah informasi dalam penggunaan obat yang terdiri darimana obat di dapatkan, bagaimana obat digunakan, bagaimana obat disimpan dan bagaiman cara obat di buang atau dimusnahkan. Metode CBIA adalah metode penyampaian dengan menjadikan peserta sebagai pelaku utama dalam kegiatan. Peserta menggunakan 
lembar kerja untuk mengklasifikasikan penggolongan obat berdasarkan nama generik dan nama dagang, indikasi, efek samping dan kontra indikasi yang dipandu oleh seorang Apoteker setiap kelompok. Informasi yang didapat dari pengisian lembar kerja tersebut didiskusikan bersama dalam kelompok besar agar didapatkanpersepsi dan pengetahuan yang sama seluruh kelompok.

Kegiatan dilakukan dalam beberapa tahapan yaitu:

1. Penyuluhan DAGUSIBU diawali dengan penjelasan secara umum tentang tujuan pengabdian kepada peserta Kader Puskesmas Mokoau dan teknik pelaksanaan kegiatan yaitu tinjauan umum Gema Cermat dan Dagusibu.

2. Pretest dilakukan selama lebih kurang 30 menit untuk mengukur tingkat pengetahuan peserta tentang penggunaan obat yang baik dan benar.

3. Kegiatan I dilakukan dengan membentuk kelompok menjadi 5 kelompok. Tiap kelompok terdiri dari 5-6 peserta. Setelah itu dilakukan pemilihan ketua kelompok sebagai koordinator dalam melakukan kegiatan selanjutnya.

Kepada masing-masing kelompok diberikan 1 paket obat yang terdiri dari bermacam-macam obat, kemudian peserta:

4. Penyuluhan DAGUSIBU diawali dengan penjelasan secara umum tentang tujuan pengabdian kepada peserta Kader Puskesmas Mokoau dan teknik pelaksanaan kegiatan yaitu tinjauan umum Gema Cermat dan Dagusibu.

5. Pretest dilakukan selama lebih kurang 30 menit untuk mengukur tingkat pengetahuan peserta tentang penggunaan obat yang baik dan benar.

6. Kegiatan I dilakukan dengan membentuk kelompok menjadi 5 kelompok. Tiap kelompok terdiri dari 5-6 peserta. Setelah itu dilakukan pemilihan ketua kelompok sebagai koordinator dalam melakukan kegiatan selanjutnya. Kepada masing-masing kelompok diberikan 1 paket obat yang terdiri dari bermacam-macam obat, kemudian peserta:

a. Pengamatan terhadap nama bahan aktif obat dari masing-masing obat

b. Mengelompokkan obat tersebut berdasarkan jenis bahan aktif

c. Melakukan diskusi terkait pengamatan yang dilakukan dipandu oleh Apoteker

7. Kegiatan II. Setelah peserta melakukan pengelompokkan obat seperti pada kegiatan I, selanjutnya peserta melakukan pencarian informasi atau keterangan yang tertera pada kemasan obat menggunakan lembar kerja yang telah disediakan. Masing-masing peserta menuliskan informasi untuk dirinya sendiri terkait nama bahan aktif obat, mengelompokkan nama obat yang mengandung bahan aktif yang sama, aturan pemakaian, efek samping, peringatan sekaligus berdiskusi dengan fasilitator yaitu apoteker.

8. Post test. Setelah kegiatan II selesai, selanjutnya dilakukan post test untuk mengukur tingkat pengetahuan peserta setelah dilakukan kegiatan penyuluhan DAGUSIBU metode CBIA.
9. Penutupan kegiatan oleh Kepala Puskesmas Mokoau Kecamatan Mokoau Kota Kendari.

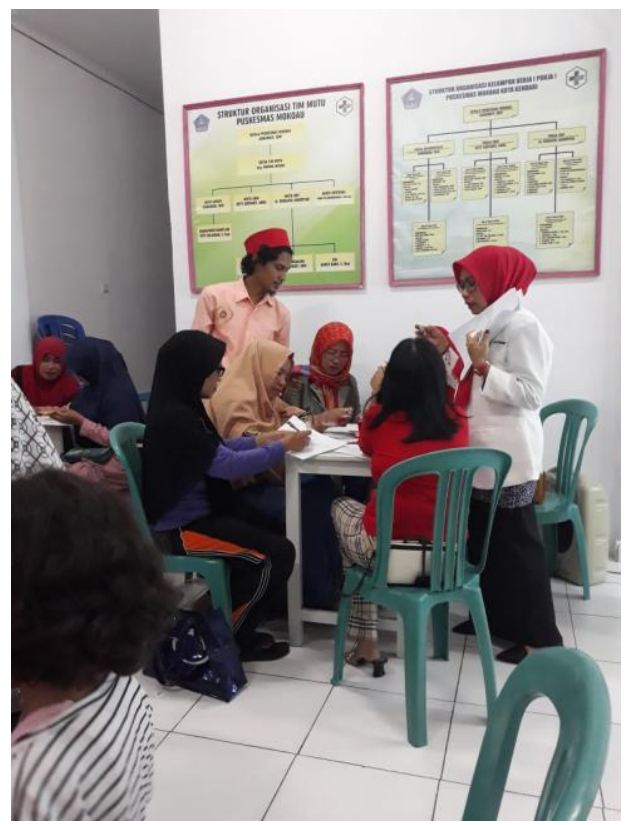

Gambar 2. Sosialisasi DAGUSIBU menggunakan metode CBIA

Sosialisasi DAGUSIBU metode Cara Belajar Insan Akatif/CBIA adalah model pembelajaran yang efektif dalam meningkatkan pemahaman masyarakat tentang penggunaan obat yang baik dan benar. Terdapat peserta yang baru mengetahui tentang kesamaan efektifitas dan kualitas antara obat generik dengan obat merek dagang dan perbedaan hanya pada harga. Cara penyimpanan adalah juga informasi yang baru bagi peserta terkait dengan tempat penyimpanan ada yang di suhu dingin yaitu $2-8{ }^{\circ} \mathrm{C}$ dan ada yang di suhu ruangan. Pada cara pemusnahan peserta mengaku baru mengetahui saat dilaksanakannya sosialisasi Dagusibu yaitu obat yang harus dipisahkan dai kemasan primernya dan dibuang dengan cara ditanam dalam tanah atau dalam kloset. Oleh karena itu DAGUSIBU metode CBIA ini perlu terus digalakan kepada seluruh lapisan masyarakat terutama tingkat keluarga melalui pemanfaatan kader puskesmas sebagai bentuk pelayanan dan pendekatan puskesmas ke masyarakat bekerjasama dengan Apoteker yang ada di PD IAI Sultra ataupun akdemisi.

\section{Kesimpulan}

Sosialisasi DAGUSIBU metode Cara Belajar Insan Akatif/CBIA adalah model pembelajaran yang efektif dalam meningkatkan pemahaman kader puskesmas tentang penggunaan obat yang baik dan benar. Anak usia sekolah wajib diingatkan dan diedukasi tentang bahaya Narkoba terutama modus penyebaran dan bentuk penyalahgunaan zat adiktif yang semakin beragam.

\section{Daftar Pustaka}

1. Kemenkes, 2011, Modul Penggunaan Obat Rasional, Kementrian Kesehatan Republik Indonesia, Jakarta 
2. Susanti S., Ratih Anggareni, Setiani S., Tri Jayanti, Wachyu Wulandari, Sudarso S., 2014, Peningkatan Pengetahuan IbuIbu Mengenai Perilaku Pengobatan Sendiri dengan Menggunakan Metode CBIA di Tiga Kabupaten di Jawa Tengah, Jurnal Pharmacy, Vol. 11, No. 01. Purwokerto

3. Budiarti I., 2016, Perbandingan Efektivitas Metode Edukasi dalam Upaya Peningkatan Pengetahuan Ibu Tentang DAGUSIBU, Skripsi, Universitas Muhammadiyah Purwokerto, Purwokerto

4. www.sultrakini.com, Bumi Anoa Darurat Narkoba, diakses tanggal 3 September 2018
5. www.kendaripos.co.id, Pemakai Narkoba di Sultra Mayoritas Pelajar Per Maret 66 Orang Terjaring BNN, diakses tanggal 30 Oktober 2018

6. Kementerian Kesehatan Republik Indonesia, 2016 , Peraturan Menteri Kesehatan Republik Indonesia No.74 tahun 2016 Tentang Standar Pelayanan Kefarmasian Di Puskesmas, Menteri Kesehatan Republik Indonesia, Jakartal

7. Wardani LA, 2018, Gambaran Penggunaan Narkotika dan Psikotropika pada Pelaku Hiburan Malam yang Diperiksa di Rumah Sakit Bhayangkara Kota Kendari Sulawesi Tenggara tahun 2015 dan 2016, Skripsi, Fakultas Farmasi Universitas Halu Oleo, Kendari 